\title{
Distracting people from sources of discomfort in a simulated aircraft environment
}

Laura Lewis ${ }^{1}$, Harshada Patel*1${ }^{1}$, Sue Cobb $^{1}$, Mirabelle $D^{\prime}$ Cruz $^{1}$, Matthias Bues ${ }^{2}$, Oliver Stefani ${ }^{2}$, Tredeaux Grobler ${ }^{2}$

*Corresponding author (t: +44 (0)115 951 4040, e: harshada.patel@nottingham.ac.uk)

${ }^{1}$ Human Factors Research Group, University of Nottingham, University Park, Nottingham, NG7 2RD, UK

${ }^{2}$ Light Fusion Lab, Fraunhofer IAO, Nobelstraße 12, 70569 Stuttgart, Germany

\begin{abstract}
BACKGROUND: Comfort is an important factor in the acceptance of transport systems. In 2010 and 2011, the European Commission (EC) put forward its vision for air travel in the year 2050 which envisaged the use of in-flight virtual reality. This paper addressed the EC vision by investigating the effect of virtual environments on comfort. Research has shown that virtual environments can provide entertaining experiences and can be effective distractors from painful experiences.
\end{abstract}

OBJECTIVE: To determine the extent to which a virtual environment could distract people from sources of discomfort.

METHODS: Experiments which involved inducing discomfort commonly experienced in-flight (e.g. limited space, noise) in order to determine the extent to which viewing a virtual environment could distract people from discomfort.

RESULTS: Virtual environments can fully or partially distract people from sources of discomfort, becoming more effective when they are interesting. They are also more effective at distracting people from discomfort caused by restricted space than noise disturbances.

CONCLUSIONS: Virtual environments have the potential to enhance passenger comfort by providing positive distractions from sources of discomfort. Further research is required to understand more fully the reasons why the effect was stronger for one source of discomfort than the other.

\section{Keywords}

Comfort, discomfort, virtual reality, virtual environments, aircraft 


\section{Introduction}

Comfort is known to be an important factor in passenger acceptance of transport systems and therefore willingness to fly again [1-3] under the same conditions. As comfort plays such an important role in passenger acceptance, improved cabin comfort can be used as a means of marketing for aircraft manufacturers and airlines [2] as was demonstrated by Airbus in 2013 when they launched an advertising campaign based on their wider seats [4].

In 2010 and 2011, the European Commission (EC) set out its vision for aviation in the year 2050, highlighting the importance of enhancing passengers' experiences [5]. Part of this vision includes the use of virtual reality (VR) to provide passengers with personalised, entertaining and friendly experiences as well as a means of 'escaping from the fast pace of society' [6]. More recently, the airline Qantas have announced a trial of VR technology in-flight to provide passengers with content such as virtual tours of Qantas destinations or viewing an Airbus A380 landing from the tarmac [7].

\subsection{Comfort and discomfort}

Although the words 'comfort' and 'discomfort' are commonly used in everyday language, definitions are widely debated in scientific literature. This debate includes deliberations as to whether comfort and discomfort can be considered to be two ends of a single continuum $[1,8]$, whether they are separate constructs with different underlying factors affecting them [9-13] or whether comfort is simply the absence of discomfort [14]. Where comfort and discomfort have been associated with different underlying factors, comfort has been associated with unexpected positive experiences [10], a sense of well-being [1, 15-18], satisfaction, ease, relief [16] and relaxation [13]. Conversely, discomfort has been associated with lack of ease [18], pain, soreness and fatigue [13]. The authors who suggest that comfort is a lack of discomfort $[14,19]$ imply that comfort is a neutral state in which people are unaware of any positive or negative feelings.

There is also discussion in the literature regarding the ways in which the experiences of comfort and discomfort interact with each other. Some authors suggest that comfort and discomfort can be experienced simultaneously and that to be in a state of comfort does not assume a complete lack of discomfort [16]. Others propose that a lack of discomfort does not always lead to comfort due to the need for the presence of different underlying factors for comfort to occur [13, 20]. In addition, it has been suggested that high levels of discomfort can only be experienced if comfort levels are low and vice versa therefore indicating that the two constructs are not completely independent of each other [20].

Regardless of the definition of 'comfort' and 'discomfort' used, there is consensus that they are both subjective concepts [9]. Comfort is always viewed as a positive and desirable state whereas discomfort is always an undesirable, negative state. Comfort and discomfort are also always viewed as a person's affective reaction to a situation or environment $[3,9]$. Therefore it could be said that an environment or a product is not, in itself, comfortable or uncomfortable but are perceived as comfortable or uncomfortable by individuals $[11,21]$ whose perceptions may change according to their states and situations.

\subsubsection{Passenger comfort}

Various factors have been suggested to influence aircraft passengers' experiences of comfort or discomfort. Some of these factors could be classified as intrinsic to an individual and may include demographics, anthropometry, physiology, health and well-being, psychology, attitudes or expectations $[3,22,23]$. These factors are often difficult or impossible to change [10] and can cause different people to experience varied levels of comfort or discomfort in identical environments. 
Factors relating to the flight situation may also affect passenger comfort. Such factors may include purpose for travel, flight time, flight duration, travel companions, cost, who has paid for the journey, the airline, the aircraft etc. [23]. As for the factors which are intrinsic to a person, many of these factors are unique to individuals and might affect the perception of comfort by different people in different ways. Furthermore, the response of individuals may vary according to specific situations. For example when taking a short journey, lower levels of comfort might be expected and required than for a long journey [24].

Other factors which may affect passenger comfort include environmental factors such as lighting, noise, temperature, humidity, motion, smells etc. [2, 3, 10, 11, 25-27]. Seating and the amount of space surrounding a person can also impact on comfort levels. This includes the design of the seat itself (e.g. headrests, armrests and seat upholstery), the amount of legroom provided [2, 3, 21, 22, $25,26]$ or the amount of space in the wider cabin environment [21]. The presence of other passengers can also affect comfort. This may be due to behaviours such as reclining their seats leading to a reduction in space [21], breaches of personal space [23] or other negative attributes such as inconsiderate behaviours or inappropriate responses to social cues [22, 23, 28]. Finally, the provision and quality of in-flight entertainment (IFE) $[21,22,25,28]$ can impact on comfort as can the ability for a passenger to carry out desired activities such as reading, sleeping, working etc. [3].

\subsection{Use of virtual environments for distraction}

To date, no studies have investigated the ways in which virtual environments (VEs) can distract people from sources of discomfort commonly experienced in-flight. However, a number of studies have investigated the ways in which VEs (such as those depicting snowy landscapes) can be used to distract people from painful experiences in either clinical or experimental settings. Many of these studies have focussed on specific elements or attributes of the VEs. For example, studies have shown that both interactive and passive VEs can increase pain tolerance [29-31] but that this effect is greater for interactive VEs $[29,30]$.

The research presented in this paper was conducted as part of the EU FP7 VR-HYPERSPACE project (AAT-285681) which aimed to use VR and mixed reality technologies in-flight to enhance aircraft passenger comfort in the year 2050 and beyond. It aimed to determine the extent to which a virtual environment which depicted the view outside of a low altitude flight, could distract people from one of two sources of discomfort which are commonly experienced in-flight (the sound of a crying baby or restricted legroom).

\section{Method}

\subsection{Participants}

Forty-three participants were recruited from Fraunhofer IAO and Stuttgart University. Thirty participants were male and 13 were female. They had a mean age of 30 years $(S D=8.73)$. All participants were required to be able to speak English and to have taken a flight in the last three years. People who had any conditions which are known to be indicators of susceptibility to virtual reality induced symptoms and effects (VRISE), for example, those in [32] were excluded from participation. Criteria included susceptibility to motion sickness, migraines, epilepsy (photosensitive or otherwise), recurring headaches, back pain or back problems, neck or shoulder pain, asthma, problems with depth perception, heart conditions or any other serious injury or illness as well as those who were pregnant. 
The participants were asked to complete a short background questionnaire which included measures of how much they like flying, are scared of flying and their experience using VR using 11 point scales. The descriptive statistics for this data are reported in table 1.

[Insert table 1]

\subsection{Equipment}

A physical aircraft cabin mock-up at Fraunhofer IAO, Stuttgart was used in this study (see figures 1 and 2). This comprised two rows of three airline seats. A bank of six 24 " monitors was positioned in front of the first row of seats to replicate seat-back displays. The seat pitches were similar to that of a typical economy aircraft cabin (approximately 32", $810 \mathrm{~mm}$ ). The dimensions of the seats (in $\mathrm{mm}$ ) and their positions with respect to each other and the seat-back displays can be found in figure 3 . Two 46" televisions were also set into the footwell of the front row of seats. All of this equipment was placed inside a four-sided Cave Automatic Virtual Environment (CAVE) which made use of 14 projectors which were placed outside of the CAVE. The VE was displayed on the CAVE walls as well as the seat-back and floor displays. Speakers were positioned outside the CAVE on the left and right hand sides of the front row of seats to provide stereo sound.

[Insert figures 1-3]

Motion tracking was integrated into the mock-up to provide motion parallax and therefore a true first-person perspective. Motion tracking was provided using an Advanced Realtime Tracking (ART) D-Track optical tracking system. This comprised two AR-TRACK 2 cameras which were positioned above the seat-back displays. These were used in combination with a pair of glasses without lenses but with markers attached (see figure 4). This technology could be used to provide motion parallax and therefore a true, first person perspective.

[Insert figure 4]

The VE used in this study depicted a surround view of the environment outside of the aircraft when taking a low-level flight (see figures 2 and 5). The VE is referred to in this paper as the 'invisible aircraft $V E^{\prime}$ and depicted a flight over the area surrounding the Fraunhofer IAO campus, an area which was familiar to all participants. This VE was selected based on ideas which emerged from early studies in the VR-HYPERSPACE project [33]. It was also selected because it fit within one of the scenarios of use which had previously been identified for VEs in an aircraft context, the enhancement of the aircraft environment [34]. The concept for the invisible aircraft VE was that it would provide passengers with an enhanced view of what would be around them in the real world. This experience would be unique to flight as it could not be experienced in the same way on the ground.

[Insert figure 5]

In all study conditions, the sound of an aircraft (engine noise and muffled conversation) was played to enhance the ecological validity of the set-up.

The participants were also exposed to one of two sources of discomfort, either the sound of a crying baby or an adjustable board which limited their legroom (see figure 6).

[Insert figure 6] 
An audio recorder was used to capture interview responses and all questionnaires were paperbased.

\subsection{Pilot testing and study refinements}

The study was piloted with two participants. As a result, the lighting inside the set-up during the no VE conditions was adjusted to ensure that it was not too dark. The exposure time to the experimental conditions was also refined to ensure that discomfort would be experienced by participants in the baseline (no VE) conditions.

\subsection{Design}

The study was a between-subjects design to eliminate a learning effect with regard to participants building up strategies to cope with any discomfort experienced. It is acknowledged that a betweensubjects design introduces a potential confounding factor of individual differences due to a lack of consistent participants across groups. However, it is likely that this effect would have a smaller impact than the effect of participants becoming more accustomed to the experimental protocol if a within-subjects design was used.

Participants were exposed to one of four experimental conditions. These are described in table 2.

\section{[Insert table 2]}

The study was designed to last no longer than 30 minutes, with 15 minutes exposure to the experimental condition. The study was approved by the ethics committee at the Faculty of Engineering, University of Nottingham.

\subsection{Procedure}

Participants took part in the study individually. They were introduced to the study before being asked to complete a demographics questionnaire and signing an informed consent form. They were told that the study was investigating the use of VEs in future aircraft and were also told whether or not they would be experiencing a VE. They were informed that either their legroom would be restricted or that they would hear the sound of a crying baby for the duration of the condition. The participants were asked to leave their belongings outside the set-up. They were told that there was no specific task for them to complete and that they should behave as they would on a real aircraft when carrying out the study. Exposure to the experimental condition lasted for 15 minutes. Participants were not told how long they would be in the experimental condition for but were aware during recruitment that their participation would be required for 30 minutes.

Those participants who experienced the limited legroom condition, were asked to put their feet back as far as they could and then the board was moved towards them until it was touching their feet. The participants' legroom was restricted at their feet rather than their knees due to the constraints of the mock-up and the position of the displays. A board was used to restrict legroom as this controlled for differences in anthropometry by restricting all participants' legroom by the same degree. It is acknowledged that as tall people will often experience restricted legroom in real flight environments, they may have existing strategies to manage this discomfort and therefore may have a higher discomfort threshold. However, a decision was made to restrict legroom in this way in order to ensure that all participants would experience discomfort. If the legroom of shorter participants was not restricted, the impact of the VEs on their discomfort would not have been measurable. 
Prior to the condition, the participants were asked to complete a short questionnaire. This comprised the short symptoms checklist (SSC) [35] and an overall rating of comfort/discomfort. Following each condition, a similar questionnaire was completed and a post-study interview was carried out. The SSC was completed solely to monitor any VRISE symptoms and was not included in any data analysis.

\section{Results}

\subsection{Quantitative data analysis}

The following sections detail the findings from the questionnaires which were issued prior to and following exposure to the experimental conditions.

\subsubsection{Subjective ratings of comfort and discomfort}

Participants were asked to rate their levels of comfort/discomfort on a seven point ordinal scale (with anchors 'extremely uncomfortable' (-3), 'neither comfortable nor uncomfortable' $(0)$ and 'extremely comfortable' (3)) both prior to and following the condition experienced. The ratings provided prior to the study referred to how the participants were feeling prior to exposure to any elements of the experimental conditions. The ratings given after the condition related to the participants' comfort/discomfort levels during the study. Participants were asked for a general rating of comfort/discomfort rather than a rating related to the restricted legroom or crying baby sound for two reasons: firstly, a general rating could be compared to ratings of their states prior to completing the study and secondly, ratings of comfort/discomfort relating to the discomfort inducing stimuli alone would not necessarily account for the effect of the distractors. Therefore, general ratings were used and interviews were carried out to further understand these ratings.

A Kruskal-Wallis test was carried out in order to determine whether there were any differences in the comfort/discomfort experiences of the participants in each group prior to completing the study. The descriptive statistics for this test can be found in table 3 and illustrated using box plots in Figure 7.

[Insert table 3]

[Insert figure 7]

No significant differences were found between the ratings $(H=1.01 ; d f=3 ; p>0.05)$, with participants generally experiencing neutral to mild comfort prior to the study. It was therefore assumed that the baseline comfort/discomfort levels experienced by participants in each of the study groups could be regarded as homogenous.

As a result of the homogeneity of the participants' comfort/discomfort levels prior to the study, a Kruskal-Wallis test with planned post-hoc Mann Whitney tests was carried out comparing the differences in ratings of comfort/discomfort during the study. The descriptive statistics for this test can be found in table 3 and box plots are shown in Figure 8. It can be seen that for all conditions apart from VELeg, there was a shift towards reports of discomfort during the study.

[Insert figure 8]

The Kruskal-Wallis test revealed a significant difference in comfort/discomfort ratings during the study $(H=13.599 ; d f=3 ; p<0.05)$. Planned post-hoc Mann Whitney tests revealed that there were no significant differences between the NoVECry and NoVELeg conditions $\left(U=54.5 ; N_{1}=11 ; N_{2}=11\right.$; 
$p>0.05)$, the NoVECry and the VECry conditions ( $\left.U=34.5 ; N_{1}=11 ; N_{2}=10 ; p>0.05\right)$ or the VECry and VELeg conditions $\left(U=28.5 ; N_{1}=10 ; N_{2}=11 ; p>0.05\right)$. There was a significant difference between the NoVELeg and VELeg conditions $\left(U=28.5 ; N_{1}=10 ; N_{2}=11 ; p<0.05\right)$. The findings indicate that the two discomfort inducing stimuli were similarly uncomfortable when no distractor was provided. It can be seen from Figure 8 that the results also indicate that the VE significantly enhanced comfort or reduced discomfort when legroom was restricted. However, the VE had no effect when the sound of a baby crying was played.

Wilcoxon tests were performed on the ratings of comfort and discomfort before and during the study for each condition to determine what effect the stimuli had on participants' perceptions of comfort/discomfort. The descriptive statistics and results of these tests can be found in table 3 
Table 3. A box plot which shows the pattern of pre- and during condition ratings of comfort/discomfort across all of the conditions can be found in Figure 9.

[Insert figure 9]

The Wilcoxon tests revealed that there were significant differences in pre- and during condition ratings for the NoVECry and NoVELeg conditions therefore indicating that the discomfort inducing stimuli were effective (see Figure 9). No significant differences were found in pre- and during the study ratings of comfort/discomfort for the VECry and VELeg conditions indicating that the VE provided was an effective distractor from the discomfort inducing stimuli (see Figure 9).

\subsubsection{Subjective ratings of presence}

After the two VE conditions, participants were asked to rate their agreement with the following statement: 'I had a strong sense of really 'being there' within the virtual environment' as a measure of their presence in the VE. Ratings were given using a five-point scale with anchors 'strongly disagree' (-2), 'disagree' (-1) 'neutral' (0), 'agree' (1) and 'strongly agree' (2). The descriptive statistics for these ratings can be found in table 4 .

[Insert table 4]

A Mann Whitney test indicated that there were no significant differences in ratings of presence in the VECry and VELeg conditions $\left(U=65.5 ; N_{1}=10 ; N_{2}=11 ; p>0.05\right)$ therefore indicating that the two discomfort inducing stimuli had similar effects to each other on presence in the VE. The descriptive statistics revealed that the participants in both conditions generally rated their presence as 'neutral'.

\subsubsection{Correlations between presence and comfort/discomfort}

Spearman tests were carried out to determine whether there was any correlation between ratings of presence and ratings of comfort/discomfort in the VECry and VELeg conditions. No significant correlations were found between presence and comfort ratings in the VECry condition $\left(r_{s}=0.425\right.$; $N=10 ; p>0.05)$ or the VELeg condition $\left(r_{s}=0.268 ; N=11 ; p>0.05\right)$. This indicates that levels of presence did not impact on comfort/discomfort experienced in either of these conditions or vice versa. However, given that these ratings were 'neutral' on average, with 'neutral' central tendencies, this finding is unsurprising.

\subsection{Qualitative data analysis}

Following exposure to the experimental conditions, interviews were conducted to ask participants about their experiences. Interview questions related to the following:

- The factors affecting the participants' comfort/discomfort.

- The participants' awareness of the discomfort inducing stimuli.

- The effect of the discomfort inducing stimuli on the participants' overall experiences.

- The strategies used to overcome the discomfort inducing stimuli.

- The effect of the VE on the participants' perceptions of the discomfort inducing stimuli. The findings resulting from these interviews are detailed in the following sections.

It should be noted that the study was carried out in Germany with participants who are not native English speakers. Therefore, quotes provided in the following sections may not be in perfect English. 


\subsubsection{Comfort and discomfort}

Following exposure to the experimental condition, participants were asked to describe the factors affecting their comfort and discomfort in an interview.

Unsurprisingly, the most commonly mentioned source of discomfort for both of the restricted legroom conditions was the limited legroom. For example, a participant in the NoVELeg condition stated,

"The limited legroom obviously. You don't have much options to move your legs into a comfortable position because there's simply no room." - P18

For some participants in the NoVELeg condition, the lack of legroom led to physical manifestations of discomfort including numbness.

"And then at a certain time then you feel numb because you cannot move (sic)" - P16

An inability to find a comfortable sitting position was another reported source of discomfort in the NoVELeg condition.

"Uncomfortable as well just trying to shift around to get more comfortable but it wasn't really possible." - P12

The lack of activity or other stimulation also led to boredom. This was reported in both the NoVELeg and the NoVECry conditions.

Apart from the limited legroom, the sources of discomfort in the VELeg condition were somewhat different to the NoVELeg condition and tended to centre on the hardware and software. For example, some participants felt that the seat-back displays were too close to them and others found that the image quality led to headaches.

"What I didn't like so much was that the build quality wasn't that good and I think when I sat so close to the computers [seat-back displays] that made me feel a little bit of headache (sic)." - P43

The main factors affecting comfort (or lack of discomfort) reported during the NoVELeg condition were the noise levels and the seats. One participant stated,

"The seat was quite alright and yeah the main thing was the seat and the sound, it wasn't too loud so the noise was quite OK. I'd say I'm used to this level of sound. Not disturbing." P42

Participants in all conditions also liked that they were able to recline their seat to create a more comfortable seating position.

"I think what I like is that I was a bit tired so I really, I moved back [reclined] the chair and I could try to relax in a way, not completely sleeping, but in that, I mean that's normally what you do in an airplane if you are not reading or watching videos... It was more comfortable but also it gives you, because it moves you back, you have more headroom and you feel obviously more...It's just more space up there [at head height] but then you close your eyes and it's more about the posture." - P16

Participants in the VELeg and NoVECry conditions also reported that not having any other participants in the adjacent seats was comfortable.

"And comfortable was that I had no seat neighbours so I can stretch out my arms a little bit and move around."- P13

The sources of comfort which were commonly mentioned in the NoVELeg condition were also present in the VELeg condition. In addition to these, participants often reported feeling relaxed and generally enjoyed watching the VE.

"I think comfortable is the sound because I like travelling in the plane and I think I associate it with being there for a while and then I think subjectively I calm down because I don't have to 
go anywhere (sic). I just have to sit in the plane and wait until I arrive somewhere and so from this experience, I think it's somehow relaxing. What I also liked and I recognised the scenery and we flew over our building and it was interesting...but the whole experience was not...intense yeah, but rather calming." - P27

A number of participants in this condition reported that although there was limited legroom, this was not disturbing or uncomfortable for them.

"Yeah there wasn't so much legroom but it wasn't disturbing for me." - P24

Some participants reported that they did not feel any discomfort or generally felt comfortable in this condition.

In the NoVECry condition, all participants mentioned that the sound of the crying baby was a source of discomfort for them.

"I heard a baby crying. I didn't like it. It was annoying in a way and the longer it didn't stop, the more it became annoying...I couldn't really chill or relax on the plane. I was in an intense mood." - P9

Some participants also commented that alongside leading to boredom, the lack of other stimuli made it more difficult to cope with or distract themselves from the sound of the baby crying in this condition.

"Yes crying and because the absence of all other effects like people so you had no possibilities to cope with the issue (sic)." - P6

The majority of participants reported that the sound of a crying baby was a source of discomfort in the VECry condition. This indicates that the presence of a VE when the sound of a crying baby was played did not have a substantial distracting effect. Other sources of discomfort in the NoVECry condition included environmental factors such as lighting or temperature and a general feeling of discomfort. For example, a participant in the NoVECry condition said,

"There was nothing that made me feel comfortable so everything was uncomfortable...The baby crying of course...nothing to do, the boredness." - P4

The amount of legroom available was also a source of discomfort for some participants in both the NoVECry and VECry conditions. A participant in the VECry condition stated,

"The less present space for my legs because I'm pretty tall. That's normal in the plane for me." - P38

It should be noted that the seat pitch in these conditions was similar to that of an average economy cabin on a present day airline (approximately 32 inches) and therefore tall participants were likely to be affected by this.

Like the VELeg condition, in the VECry condition the main source of discomfort, aside from the deliberately introduced stimuli (in this case, the sound of a baby crying), was the VE hardware and software. Specific sources of discomfort included vertigo, blurry images and headaches caused by the wearing the tracking glasses, for example:

"And it was also uncomfortable when the vision was not clear on the front screens...Some of the times and also on the foot row [floor], it's extremely blurred." - P36

Sources of comfort which were reported during the NoVECry condition included legroom for one participant and, more generally, the seats and environmental factors such as the sound of the aircraft engines or the lighting. In the VECry condition, an additional source of comfort was the interesting view portrayed in the VE. One participant also commented that the VE created an opportunity to have a view, even when sitting in the middle seat.

"Yeah there was the view of the area around. I think it's a really nice idea to have. Also in the middle seat, opportunity to have some experience and some impressions from the outside world and that you can look around what's going on outside and where are you and what's there, in which area. And it's also interesting because the university campus of course." - P30 
Some participants also commented that the VE was calming and distracted them from the sound of the baby crying.

"Yeah because it was just going on and on and it was just calming, sort of and I even, at times, didn't really hear the baby crying anymore." - P35

It is evident from these findings that the discomfort inducing stimuli and the VE were the main factors contributing to participants' comfort or discomfort experiences. However, other factors such as the seat and the legroom (in the crying baby sound conditions) also played a part and would have contributed to their subjective ratings.

\subsubsection{Awareness of discomfort inducing stimuli}

Participants were asked whether or not they were aware of the discomfort inducing stimuli during the condition experienced. Some participants in the NoVELeg reported that they were always aware of the board in front of their legs, with one stating that it was difficult to forget about this. A small number of participants reported that they sometimes forgot about the board in this condition but that for the most part, they were aware.

"I tried to close my eyes and forget about it but I think most of the time, I was aware of it. I tried to distract me but I think it didn't have much [effect]... (sic)" - P13

Of the participants who reported that they were able to forget about the board in this condition, one participant stated that they were only aware of the board when they needed to move their legs.

"Only when I needed to move my legs. So basically when the position got really uncomfortable and tried to shift, yeah can't shift my legs." - P12

Another participant stated that they were unaware of the board when they had found a comfortable position to sit in. Other participants were able to relax, doze or think about other things and therefore forget the limited legroom momentarily. Only one participant in this condition was able to completely forget about the board in front of their legs and attributed this to thinking about something else.

A number of participants in the VELeg condition reported that they were mostly or completely unaware of the board in front of their legs. The reasons that participants attributed to forgetting about the board in this condition generally related to the characteristics of the VEs, for example, when the resolution was higher or when the VE was interesting (e.g. over the city).

"I think I realised the space and the feet board when I was bored when the environment was only trees and then it was boring and then I would recognise it and then when the city came and the HDM and Fraunhofer and I looked where the streets are, 'ah ok' and then I forget it and then I was bored and I realised it." - P25

In contrast, when the VE was boring (e.g. over the countryside) or when it was of a lower resolution, participants tended to become more aware of the board.

"Maybe the resolution of the picture was bad. When it was high definition picture, I thought, 'ah great, I recognise the university and so' and then there was forest and not as good as before and I realised, 'oh something hurts my leg'." - P29

It should be noted that the image resolution was better in the urban than the rural elements of the VEs.

Other occasions at which some participants became aware of the board in front of their legs were when they needed to move their legs or felt their leg muscles tense. In contrast, some participants did not feel a need to move their legs and therefore didn't notice the board. This may have been due to the short exposure time and may have changed if the study was carried out for the duration of a flight. Some participants also reported that they only became aware of the board when they looked down at the displays beneath their feet. 
"It's only when I watched on the floor to see what's under me, I saw it...but when I looked left, right or up, I didn't recognise it." - P40

Similarly to the NoVELeg condition, in the NoVECry condition some participants stated that they were always aware of the sound of the crying baby, often reporting that it was difficult to forget about this sound.

"I was really aware what she was doing because there was nothing else that could shift my point of focus" - P4

Some participants in this condition reported that they were mostly aware of the sound of the crying baby but did manage to forget about the sound at times. Occasions when participants were able to forget about the sound of the crying baby included when they were resting or relaxing, when the sound became monotonous or when they were thinking about something else.

"I tried to think about something so I don't notice the sound so much anymore and it worked for a short while. When I was thinking about stuff then I forgot about the crying for a short time." - P9

During the VECry condition, some participants were always aware of the sound of the crying baby whilst others reported that they were able to completely forget about the sound. A large proportion of the participants experienced variable levels of awareness of the crying baby sound (i.e. moments when they were more aware and other moments when they were less aware).

"I even, at times, didn't really hear the baby crying anymore. Once in a while, you know, I realised it but it was not disturbing. Normally it's very disturbing during a flight but it wasn't because I was just looking at the environment and just enjoying it and then I realised, 'oh I haven't heard the baby, is it still crying?'. So that was kinda nice." - P35

Similarly to the VELeg condition, participants often reported that they became more aware of the sound of the crying baby when the VE was boring (e.g. over the countryside) and less aware when they were interested in the VE (e.g. over the city).

"Well it depends on what I saw in the environment. When I was flying above the city or above the buildings, then I had a lot to look at and when I was flying over the woods, then I was bored by the vision so I heard the baby more." - P37

\subsubsection{Effect of the discomfort inducing stimuli on the participants' overall experiences}

The participants were asked to describe the effect that the discomfort inducing stimuli had on their overall experiences. During the NoVELeg condition, some participants reported that the board in front of their legs did not have any effect on their experience or comfort but that after a longer period of time, they would become uncomfortable.

"If it was any longer than 15 minutes, I would have been really uncomfortable so now it's after 15 minutes, I don't have stiff legs or anything but that would have definitely happened. That would affect my overall comfort." - P12

Unsurprisingly, many participants reported that the board in front of their legs restricted their legroom, making them generally feel restricted and unable to move, highlighting the importance of perceived control.

"I think it obviously restricts your legroom and that leads to a little bit more discomfort but on the other hand, I think for the overall comfort, I don't think that it's everything. It's a kind of, it's a physical emanation of what you feel. You feel restricted and this is obvious that at some points, you touch something and you cannot move." - P16

Feelings experienced during this condition included annoyance and stress as well as a compulsion to move because they knew that they were not able to do so.

"It takes away your space and it takes away the ability to shift in your seat. You want to shift positions after a while. It wasn't that bad because it wasn't a long time compared to a real 
flight but just sitting in the same position for a long time is uncomfortable and to take away that option already in your head does something with you." - P18

One participant also stated that restricted legroom is just one of a number of factors which, in combination, can induce discomfort on an aircraft and that the attenuation or removal of this factor alone would not automatically lead to a comfortable situation.

"I wouldn't say this is the most or the worst thing and if you remove that then I'm happy. It's just one of the bits and pieces which count up to feeling [uncomfortable]." - P16

During the VELeg condition, a number of participants reported that the board in front of their legs did not affect their experience, in particular when they were looking at or interested in the VE.

"Not really [board didn't affect experience]...I was looking at the scenery and heard the sound from the plane flying. I didn't pay so much attention on the board." - P27

One participant stated that when they were bored during the countryside elements of the VE, the board had a negative impact on their experience.

"I think negatively. I would say it would be much better without the board and maybe the not interesting parts like with less resolution and the forest, I think it wouldn't be as bad as it was for me because of the board." - P29

Another participant stated that they found the board "disturbing" (P28) in general.

In the NoVECry condition, all participants were negatively affected by the sound of a crying baby. Many participants found the sound of a crying baby to be overpowering in terms of affecting their ability to concentrate on other things, to relax or their ability to overcome the sound.

"It was also distracting me, like I couldn't concentrate on anything else." - P8

Feelings experienced as a result of the sound of a crying baby in this condition included annoyance, stress, discomfort and anger.

"I heard a baby crying. I didn't like it. It was annoying in a way and the longer it didn't stop, the more it became annoying." - P9

One participant also commented that they perceived time to pass more slowly in this condition.

"It felt like the time was running very slow. If I think about a long distance flight like this, it would be horrible." - P4

In the VECry condition, some participants did not think that the sound of a crying baby affected their experience or were able to overcome the sound after a period of time.

"It had a little [effect] because in the beginning, it was really disturbing and since I don't have kids myself, kids crying is always kinda disturbing to me because I'm just not used to that sound. So in the beginning, it was really disturbing but as I said, after a while, I just didn't hear it." - P35

Some participants in this condition found the sound of a crying baby to be overpowering in terms of either always being present or affecting their ability to concentrate.

"I mean it's annoying, you can't...concentrate on thoughts easily. So it's harder to think about something. You get distracted." - P32

Feelings experienced as a result of the sound of a crying baby included annoyance, stress and a lack of relaxation.

"I think it was because it was present all the time, it didn't stop...so perhaps because of this constant noise, it was always there and annoying." - P38

\subsubsection{Strategies used to overcome discomfort inducing stimuli}

The participants were asked to report whether they used any techniques or strategies to overcome the discomfort inducing stimuli. During the NoVELeg condition, the most commonly reported strategy was for participants to try to find a more comfortable sitting position. 
"Really I put the back of my foots up and so for normal it was too small to the space for the feet. Five or ten centimetres more would have done better." - P42

Often, participants would position their legs in such a way that more space was created. This included crossing their legs, moving them to the sides or tilting their feet so that only their toes were in contact with the ground.

"Yeah I tried to give my legs a little more room by crossing my feet. That was a little better but not much." - P18

A number of participants in this condition tried to relax or doze in order to overcome the restricted legroom.

"The only strategy is sort of relax and try to sleep. So find a comfortable sleep position or change positions because there is no really comfortable solution. So this is what I do." - P21

Other participants tried to distract themselves from the restricted legroom by thinking about other things.

"I tried to look for something to stimulate my mind... work basically. Tried to either get my mind on a problem I'm currently having to solve, thinking about nothing, tried to listen to noises...I didn't forget that I'm not fully able to move. Didn't really work." - P12

Of the participants who reported on the effectiveness of their chosen strategies in this condition, some stated that they did not help them, some felt that their strategy made the situation more comfortable and one participant reported that their strategy helped for periods of time.

"I tried to get a more comfortable position, had one for a while then it didn't work anymore, tried to shift again and yes." - P12

In the VELeg condition, some participants reported that they did not use any strategies. Of those participants, most found that they were looking at the VE but reported that this was not a deliberate strategy.

"Yeah I think I just concentrated on the pictures so I didn't need a technique to forget about it." - P43

Like the NoVELeg condition, some participants adjusted their sitting position in order to feel more comfortable, some tried to sleep or relax and others tried to distract themselves, either through deliberately concentrating on the VE or by thinking about something else. One participant thought about the length of the experiment and used this as reassurance that they would not be experiencing this condition for too long.

"I tried to think about the whole experiment and thought 'only 20 minutes' and so not as bad." - P29

During the NoVECry condition, participants frequently tried to distract themselves from the sound of the crying baby. They often did this by thinking about something else or by trying to find something interesting in their environment.

"Yes I tried to think about something so I don't notice the sound so much anymore and it worked for a short while. When I was thinking about stuff then I forgot about the crying for a short time. And I tried to look through the plane if I can see something new or can see the baby maybe or something but I didn't see anything." - P9

Some participants tried to sleep or relax during this condition and others tried to analyse the musical elements of the sound of the crying baby.

"I was trying to find the rhythm for the baby crying" - P4

Some participants in this condition did not use any strategies to cope with the sound of a crying baby. Of those who reported on the effectiveness of their strategies, some stated that these did not help them and some stated that their strategies led them to become unaware of the sound of the crying baby. 
"I was a little bit surprised but sometimes it works really and then you don't hear the sound of the baby crying." - P5

In the VECry condition, some participants reported that they did not use any strategies to cope with the sound of a crying baby. Similarly to the NoVECry condition, of those who did use strategies, common approaches included relaxation and trying to distract themselves. Methods of distraction included concentrating on the VE and thinking about other things.

"Looking around and be interested in the simulation and in the details of the simulation and yeah to focus on other topics." - P30

Of those who reported on the effectiveness of their strategies, some stated that the strategies used were helpful and one reported that the crying baby dominated the situation.

\subsubsection{Effect of virtual environments on perceptions of discomfort inducing stimuli}

The participants in the VELeg and VECry conditions were asked to describe the effect that they thought the VE had on their perceptions of the discomfort inducing stimuli. In the VELeg condition a number of comments were made regarding the VE being an effective distractor from the restricted legroom.

"If I would not have this visual and audio stimulus, I would maybe focus more on the board or on being constrained in the seat or not being able to stand up so in that respect, I think it diverted my attention." - P27

When the VE was interesting, participants found it was particularly distracting from the restricted legroom. Conversely, when the VE was boring, it was less effective as a distractor.

"I think something like... when I was bored, I realised it and when the virtual environment was attractive or nice, I forget it and focussed on the view." - P25

One participant stated that regardless of the fact that their legroom was constrained, the VE gave them an overall feeling of spaciousness all around them.

Some participants in this condition did not think that the VE affected their experience of the limited legroom, thinking that their perception of the board in front of their legs would have been the same without a VE.

"The problem with the legs is always present during the whole flight and I don't think that it would make any changes if the environment is there or not there." - P22

Other participants felt that the effect of the VE was no different to activities that they might currently use on aircraft to distract themselves in this situation.

"Would be the same if I would have something to read or a laptop. I would read for one and a half, two hours and then I would start trying to move." - P24

In the VECry condition, most participants thought that the VE had a positive effect on their perception and experience of the sound of a crying baby, giving reasons such as it helped them to relax, gave them something to look at or distracted them.

"It's very interesting. You look and you don't hear the baby. But the baby here is extremely loud." - P33

Some participants did not think that the VE had an effect in this condition giving the reason that the sound of the baby is dominant.

"It's too dominant. I think it's a possibility to maybe forget the time or some other things you can forget but just crying is unforgettable or not not hearable. It's always present in the situation and I guess the time is one of the most factors. Maybe the space, the room around you, something like that. That are things you can forget but the dominant and present thing is not easy to ignore it." - P30 


\section{Discussion}

This paper presents a study which aimed to determine the effectiveness of an invisible aircraft VE at distracting participants from two sources of discomfort: limited legroom or the sound of a crying baby. These sources of discomfort were selected as they differed in terms of the sensory modalities through which they are perceived.

The main finding was that the participants reported that they felt more comfortable when a VE was present than when it was not and that this effect was stronger when their legroom was restricted than when the sound of a crying baby was played. This finding was consistent amongst both the subjective ratings of comfort/discomfort and the interview responses. The findings indicated that the VE had a comfort-enhancing effect therefore indicating that it overpowered the discomfort inducing stimuli to some degree, leading to a state of comfort or reduced discomfort. This contrasts with previous research which proposed that discomfort will always dominate comfort [36]. The findings also indicated, in agreement with existing research [16], that comfort and discomfort can be experienced simultaneously. This was particularly evident in the VECry condition where participants experienced comfort resulting from elements of the VE as well as discomfort associated with the crying baby sound. The findings of this study therefore also contrast with the suggestion that comfort can only be experienced during low levels of discomfort [20]. Although participants were able to experience comfort and discomfort simultaneously, they were also able to rate their overall comfort levels and therefore select whether their comfort dominated their discomfort or vice versa.

The increase in comfort in the VELeg and VECry conditions compared to the no VE equivalents could be attributed to the VE providing a distraction therefore leading to a reduction in awareness of the discomfort inducing stimuli. Participants reported that they were less aware of these stimuli when the VE was interesting (e.g. over the city where the view was more varied) and became more aware of them when the VE was boring (e.g. over rural areas where there was little variety in the environment). This corresponds with the finding that the effectiveness of VEs at distracting from pain increases with their levels of engagement $[37,38]$. Reports of emotional responses such as stress or annoyance were also reduced with the addition of the VE and fewer strategies were employed to overcome discomfort, indicating that the VE provided a positive distraction.

It should be noted that this study only tested the extent to which a VE could distract people from discomfort for a short period of time. It is not clear whether this effect would remain for the duration of a flight although the findings indicate that if the VEs provided are interesting, they are more likely to distract people from sources of discomfort. However, there may be occasions when people are made aware of sources of discomfort, even when distracted. For example, when legroom is restricted, naturally adjusting their sitting position could lead passengers to become aware of the limited space surrounding them which could, in turn, increase their discomfort. It is also important to note that VEs are likely to only distract people from discomfort if experiencing the VEs themselves is consistent with their desired activities. Further, some level of comfort may be required to be able to perform desired activities such as reading or sleeping [3] and not being able to perform these activities may result in discomfort [39].

Some researchers have also shown that discomfort increases over time. For example, it has been noted that much of the discomfort that accumulates during a day when sitting in an office environment, appears to be associated with the passage of time rather than chair's design, though it is not clear how transferable these findings are to an aircraft environment [20]. More recently, it was reported that passengers' comfort declines during a four hour flight but increases when flying more than five hours, perhaps due to the greater comfort of wider body jets [10]. In addition, people are likely to have different expectations for short-haul and long-haul flights - they may be 
more willing to accept discomfort during a short flight, knowing that it will be over soon and they may be more likely to plan for overcoming discomfort during longer flights. Therefore, more research is required to study the effects of VEs as a means to distract people from discomfort for long periods of time as well as the role of people's expectations of comfort and discomfort and their perceived ability to influence these.

Although the results of this study indicate that VEs can effectively distract people from the discomfort associated with restricted legroom, the authors do not suggest that legroom should be further reduced on passenger aircraft. As well as the possible health implications of reduced legroom, there are safety guidelines which stipulate minimum seat pitch [40]. The results of this study simply suggest that in a worst-case scenario, where a person does not have enough space for their legs due to the combination of their anthropometry and the available legroom, their discomfort may be alleviated by using VEs. However, it is not known how long this effect would last for.

It is unclear from this study why the VE distracted participants more from the limited legroom than from the sound of a crying baby. It is possible that this is due to the specific sources of discomfort and ease of overcoming these but it could also be due to the combinations of sensory modalities through which the stimuli are perceived. Within the context of this study, multiple resources theory [41] would suggest that a visual distractor would be more effective when the discomfort inducing stimulus was also perceived visually. This may partially explain the findings of this study as the VE was found to be less effective at distracting from the crying baby (auditory stimulus) than the limited legroom, the perception of which has a visual element (i.e. people can see that their space is restricted) but is predominantly tactile.

Capacity theories of attention [42] might also explain the findings in terms of the attentional resources that the discomfort inducing stimuli demand. These theories might suggest that the crying baby sound demanded more attention than the restricted legroom, therefore leaving less available resources to attend to the VE. An explanation for why the crying baby sound might demand a greater attentional resource could be due to a visceral response to the sound of the crying baby. Such responses have been described as being biologically-based automatic reactions to the perceptual properties of a stimulus without any interpretation [43]. Even though participants were aware that this sound was only a recording, the sound itself could trigger a biological or evolutionary response which has been found to manifest in adults as a state of high alert in preparation to respond to the baby's distress [44]. Many participants reported that the sound of the crying baby overpowered the VE and therefore it is possible that the VE was not compelling enough or was of the wrong type of sensory input to be fully effective in this situation. Further investigation should determine whether an auditory distractor would have a greater effect than a visual one.

Although the between-subjects design may have influenced the study's results, it was felt that a within-subjects design was more likely to cause a learning effect with regards to coping mechanisms to reduce the discomfort experienced by the sound of a baby crying or the restricted legroom. Another factor which could have influenced the results is the background of the participants who had a mean age of 30 and were recruited from a research institute/university. These participants may be more familiar with, and/or receptive to, technologies than people from other age groups or backgrounds; therefore the study would need to be repeated with a range of different people before drawing any firm conclusions. It should also be noted that the participants were not generally native English speakers and therefore were not speaking their mother tongue. This may have had some influence on the results obtained. However, measures were taken to reduce the influence of this by only recruiting people who could speak English and ensuring that a person who was fluent in both English and German was available for translation if required. 
It is acknowledged that general perceptions of the VE were not measured without one of the sources of discomfort in this study. However, an earlier within-subjects study was carried out in the same physical aircraft mock-up to investigate the influence of this VE on comfort (with and without motion tracking) compared to a baseline 'no VE' condition. Discomfort was not specifically induced in this study: any discomfort arose from the mock-up of the air cabin. Participants in this study experienced more positive emotions in the VE condition than in the baseline condition; some found that the VE created an illusion of increased physical space and had a positive impact on environmental comfort as a result of better lighting; and some participants found that viewing the invisible aircraft VE made time pass more quickly than in the no VE condition [45].

Although it was outside the scope of the current study, it would be interesting to investigate whether people who have children and those who do not, experience similar levels of discomfort when they hear the sound of a crying baby. A future study might also investigate the effects of the VE on people with hyperacusis when exposed to the sound of a baby crying, and likewise the effect of the VE on tall people when experiencing restricted legroom.

\section{Conclusion}

This research has identified that VEs can be an effective way of distracting passengers from some sources of discomfort for short periods of time, in particular, when a passenger has a limited amount of legroom. The findings indicate that when the VE provided is interesting, participants are less aware of the sources of discomfort. The findings of this study also suggest that the VE used had some effect at distracting participants from the sound of a crying baby but this was not as strong as when legroom was restricted. Further research should investigate whether this was due to the combination of sensory inputs or due to the nature of the specific discomfort inducing stimulus.

This research took a new approach to measuring the effect of interventions on perception of sources of discomfort. Inducing discomfort in order to measure the effect of a distractor was found to be an effective approach.

\section{Acknowledgements}

This research received funding from the EC FP7 project VR-HYPERSPACE (AAT-2011-RTD-1-285681 www.vr-hyperspace.eu).

\section{References}

[1] Richards LG. On the Psychology of Passenger Comfort. In: Oborne DJ, Levis JA, editors. Human Factors in Transport Research Volume 2. 2. London: Academic Press Inc. (London) Ltd.; 1980. p. 15-23.

[2] Richards LG, Jacobson ID. Ride Quality Evaluation 1. Questionnaire Studies of Airline Passenger Comfort. Ergonomics. 1975;18(2):129-50.

[3] Richards LG, Jacobson ID, Kuhlthau AR. What the passenger contributes to passenger comfort. Applied Ergonomics. 1978;9(3):137-42.

[4] Airbus. You'd never accept this, would you? \#AirbusComfort 2013 [cited 2014 15th October]. Available from: https://twitter.com/Airbus/status/394583275580051456.

[5] European Commission. Flightpath 2050 Europe's Vision for Aviation: Maintaining Global Leadership and Serving Society's Needs. Report of the High Level Group on Aviation Research. Belgium: European Union, 2011. 
[6] European Commission. Beyond Vision 2020 (Towards 2050): A Background Document from ACARE (The Advisory Council for Aeronautics Research in Europe). Brussels: European Commission; 2010.

[7] Qantas. Qantas \& Samsung unveil industry-first virtual reality experience for travellers 2015 [cited 2015 15th February]. Available from: http://www.qantasnewsroom.com.au/mediareleases/qantas-samsung-unveil-industry-first-virtual-reality-experience-for-travellers.

[8] Shackel B, Chidsey KD, Shipley P. The Assessment of Chair Comfort. Ergonomics. 1969;12(2):269-306.

[9] De Looze MP, Kuijt-Evers LFM, Van DieëN J. Sitting comfort and discomfort and the relationships with objective measures. Ergonomics. 2003 2003/08/01;46(10):985-97.

[10] Vink P, Brauer K. Aircraft interior comfort and design. Boca Raton: Taylor and Francis; 2011.

[11] Vink P, De Looze MP, Kuijt-Evers LFM. Theory of Comfort. In: Vink P, editor. Comfort and Design Principles and Good Practice. Boca Raton: CRC Press; 2005. p. 13-32.

[12] Vink P, Hallbeck S. Editorial: Comfort and discomfort studies demonstrate the need for a new model. Applied Ergonomics. 2012;43(2):271-6.

[13] Zhang L, Helander MG, Drury CG. Identifying factors of comfort and discomfort in sitting. Human Factors. 1996;38(3):377-89.

[14] Branton P. Ergonomic research contributions to design of the passenger environment. In: Oborne DJ, Branton R, Fernando L, Shipley P, Steward T, editors. Person-Centred Ergonomics: A Brantonian View of Human Factors. Boca Raton: CRC Press; 1993. p. 111-22.

[15] Kolcaba KY. A Taxonomic Structure for the Concept Comfort. Image: the Journal of Nursing Scholarship. 1991;23(4):237-40.

[16] Kolcaba KY, Kolcaba RJ. An analysis of the concept of comfort. Journal of Advanced Nursing. 1991;16(11):1301-10. PubMed PMID: 1992136866. Language: English. Entry Date: 19920301.

Revision Date: 20120302. Publication Type: journal article.

[17] Oborne DJ, Clarke MJ. The Development of Questionnaire Surveys for the Investigation of Passenger Comfort. Ergonomics. 1973;16(6):855-9.

[18] Tutton E, Seers K. An exploration of the concept of comfort. Journal of Clinical Nursing. 2003;12(5):689-96.

[19] Hertzberg HTE. Seat Comfort. Ohio: United States Air Force, 1958.

[20] Helander MG, Zhang L. Field studies of comfort and discomfort in sitting. Ergonomics. 1997;40(9):895-915.

[21] Vink P, Bazley C, Kamp I, Blok M. Possibilities to improve the aircraft interior comfort experience. Applied Ergonomics. 2012;43(2):354-9.

[22] Bor R. Psychological factors in airline passenger and crew behaviour: A clinical overview. Travel Medicine and Infectious Disease. 2007;5(4):207-16.

[23] Patel H, Lewis L, Cobb S, D'Cruz M, Tedone D, Hakulinen J. VR-HYPERSPACE deliverable D1.1 Report of current scenarios \& case definition. http://www.vr-hyperspace.eu/about-vr-

hyperspace/publicdocuments/deliverables/84-d1-1: 2012 Contract No.: VR HYPERSPACE FP7-AAT2011-RTD-1-285681.

[24] Mayr R. Comfort in Railway Travel. An examination of the fundamentals influencing vehicle design. The Railway Gazette. 1959;3:266-9.

[25] Ahmadpour N, Lindgaard G, Robert J-M, Pownall B. The thematic structure of passenger comfort experience and its relationship to the context features in the aircraft cabin. Ergonomics. 2014 2014/06/03;57(6):801-15.

[26] Hinninghofen H, Enck P. Passenger well-being in airplanes. Autonomic Neuroscience. 2006;129(1-2):80-5.

[27] Huang Y, Griffin MJ. The relative discomfort of noise and vibration: effects of stimulus duration. Ergonomics. 2014 2014/08/03;57(8):1244-55.

[28] Budd LCS. On being aeromobile: airline passengers and the affective experiences of flight. Journal of Transport Geography. 2011;19(5):1010-6. 
[29] Law EF, Dahlquist LM, Sil S, Weiss KE, Herbert L, Wohlheiter K, et al. Videogame distraction using virtual reality technology for children experiencing cold pressor pain: The role of cognitive processing. Journal of pediatric psychology. 2011;36(1):84-94.

[30] Dahlquist LM, McKenna KD, Jones KK, Dillinger L, Weiss KE, Ackerman CS. Active and passive distraction using a head-mounted display helmet: effects on cold pressor pain in children. Health Psychology. 2007;26(6):794.

[31] Weiss KE, Dahlquist LM, Wohlheiter K. The Effects of Interactive and Passive Distraction on Cold Pressor Pain in Preschool-aged Children. Journal of Pediatric Psychology. 2011 January 29, 2011.

[32] Ramsey AD. Virtual reality induced symptoms and effects, a psychophysiological perspective: University of Nottingham; 1999.

[33] Tedone D, Patel H, D'Cruz M. VR-HYPERSPACE deliverable D1.3 Report of future scenarios and case definition 2012.

[34] White JN. A history of inflight entertainment. 2011.

[35] Cobb SVG, Nichols SC, Wilson JR. Health and Safety Implications of Virtual Reality: In search of an experimental methodology. Proceedings of FIVE'95 Conference, Framework for Immersive Virtual Environments; 18th December 1995; London1995. p. 227-42.

[36] Kuijt-Evers LFM, Twisk J, Groenesteijn L, De Looze MP, Vink P. Identifying predictors of comfort and discomfort in using hand tools. Ergonomics. 2005 2005/05/15;48(6):692-702.

[37] Hoffman HG, Patterson DR, Carrougher GJ, Sharar SR. Effectiveness of virtual reality-based pain control with multiple treatments. The Clinical journal of pain. 2001;17(3):229-35.

[38] Shahrbanian S, Ma X, Aghaei N, Korner-Bitensky N, Moshiri K, Simmonds MJ. Use of virtual reality (immersive vs. non immersive) for pain management in children and adults: A systematic review of evidence from randomized controlled trials. European Journal of Experimental Biology. 2012;2(5):1408-22.

[39] Oborne DJ. Passenger comfort - An overview. Applied Ergonomics. 1978;9(3):131-6.

[40] Civil Aviation Authority. CAP 747 Mandatory Requirements for Airworthiness. Section 2, Part 3, Generic Requirements GR No 2 Minimum Space for Seated Passengers2011. p. Section 2 Part 3 Pages 1-3.

[41] Wickens CD. Multiple resources and performance prediction. Theoretical Issues in Ergonomics Science. 2002 2002/01/01;3(2):159-77.

[42] Kahneman D. Attention and Effort. New Jersey: Prentice Hall Inc; 1973.

[43] Norman DA, Ortony A. Designers and users: two perspectives on emotion and design. Foundations of Interaction Design; November 2003; Ireva, Italy2003.

[44] Giardino J, Gonzalez A, Steiner M, Fleming AS. Effects of motherhood on physiological and subjective responses to infant cries in teenage mothers: A comparison with non-mothers and adult mothers. Hormones and Behavior. 2008 1//;53(1):149-58.

[45] Lewis L. Investigating the ways in which virtual environments could influence aircraft passengers' comfort and experiences: University of Nottingham; 2015. 


\section{Tables}

Table 1 Descriptive statistics for background data

\begin{tabular}{|c|c|c|}
\hline & Median (IQR) & Anchors \\
\hline \multirow[t]{2}{*}{ Like flying } & $7(1)$ & $0=\mathrm{I}$ hate flying \\
\hline & & $10=I$ love flying \\
\hline \multirow[t]{2}{*}{ Scared of flying } & $2(2.5)$ & $0=$ Not at all scared \\
\hline & & $10=$ Extremely scared \\
\hline \multirow[t]{2}{*}{ VR experience } & $6(6)$ & $0=$ No experience \\
\hline & & $10=$ Extremely experienced \\
\hline
\end{tabular}


Table 2 Description of study conditions

\begin{tabular}{lll}
\hline Abbreviation & Description of condition & $\begin{array}{l}\text { Total number of } \\
\text { participants }\end{array}$ \\
\hline NoVECry & $\begin{array}{l}\text { No VE with an auditory source of discomfort (sound of } \\
\text { a baby crying) }\end{array}$ \\
NoVELeg & $\begin{array}{l}\text { No VE with a tactile source of discomfort (restricted } \\
\text { legroom) }\end{array}$ \\
VECry & $\begin{array}{l}\text { Invisible aircraft VE with an auditory source of } 11 \\
\text { discomfort (sound of a baby crying) } \\
\text { Invisible aircraft VE with a tactile source of discomfort } \\
\text { VELeg }\end{array}$ & 11 \\
\hline
\end{tabular}




\begin{tabular}{llll}
\multicolumn{2}{l}{ Table 3 Descriptive statistics and results of Wilcoxon tests for ratings of comfort/discomfort prior to and during the study } \\
\hline Condition & $\begin{array}{l}\text { Median } \\
\text { comfort/discomfort } \\
\text { rating prior to the study }\end{array}$ & $\begin{array}{l}\text { Median } \\
\text { comfort/discomfort } \\
\text { rating during the study } \\
\text { (IQR) }\end{array}$ & $\begin{array}{l}\text { Results of Wilcoxon tests } \\
\text { comparing pre- and during- } \\
\text { ratings }\end{array}$ \\
\hline NoVECry & $0(2)$ & $-1(2)$ & $(W=2.5 ; N=10 ; p<0.05)^{*}$ \\
NoVELeg & $1(1)$ & $-1(1.5)$ & $(W=2.5 ; N=10 ; p<0.05)^{*}$ \\
VECry & $0.5(2)$ & $0(1.75)$ & $(W=9.5 ; N=8 ; p>0.05)$ \\
VELeg & $1(2)$ & $2(1.5)$ & $(W=9 ; N=7 ; p>0.05)$
\end{tabular}

${ }^{*}$ Result significant at $p<0.05$ 
Figures

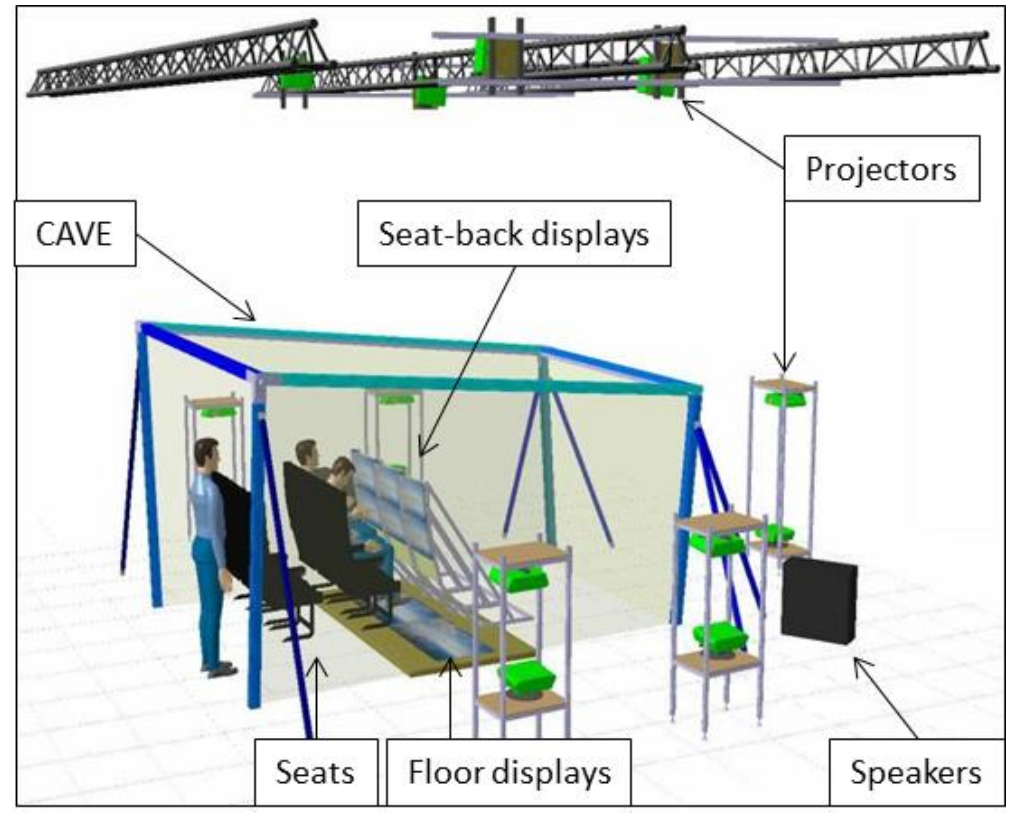

Figure 1 Fraunhofer IAO physical cabin mock-up 


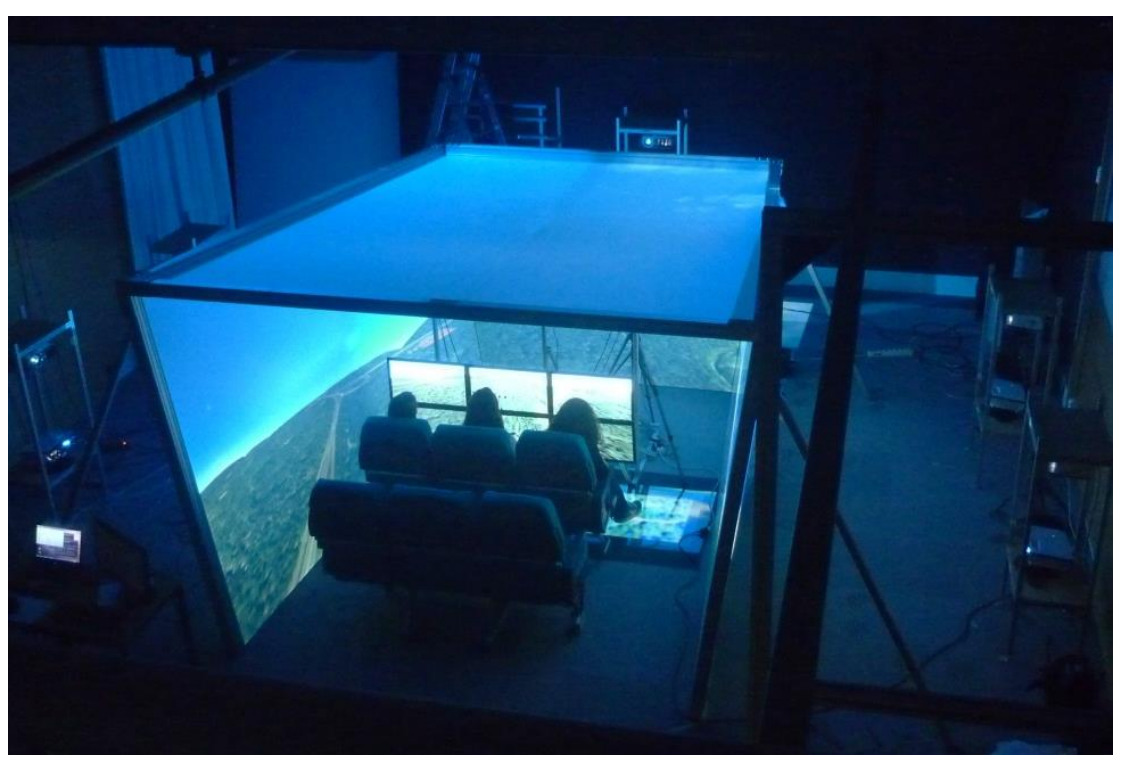

Figure 2 Fraunhofer IAO physical cabin mock-up (note that this image is indicative of the set-up and was not taken at the time of the study) 


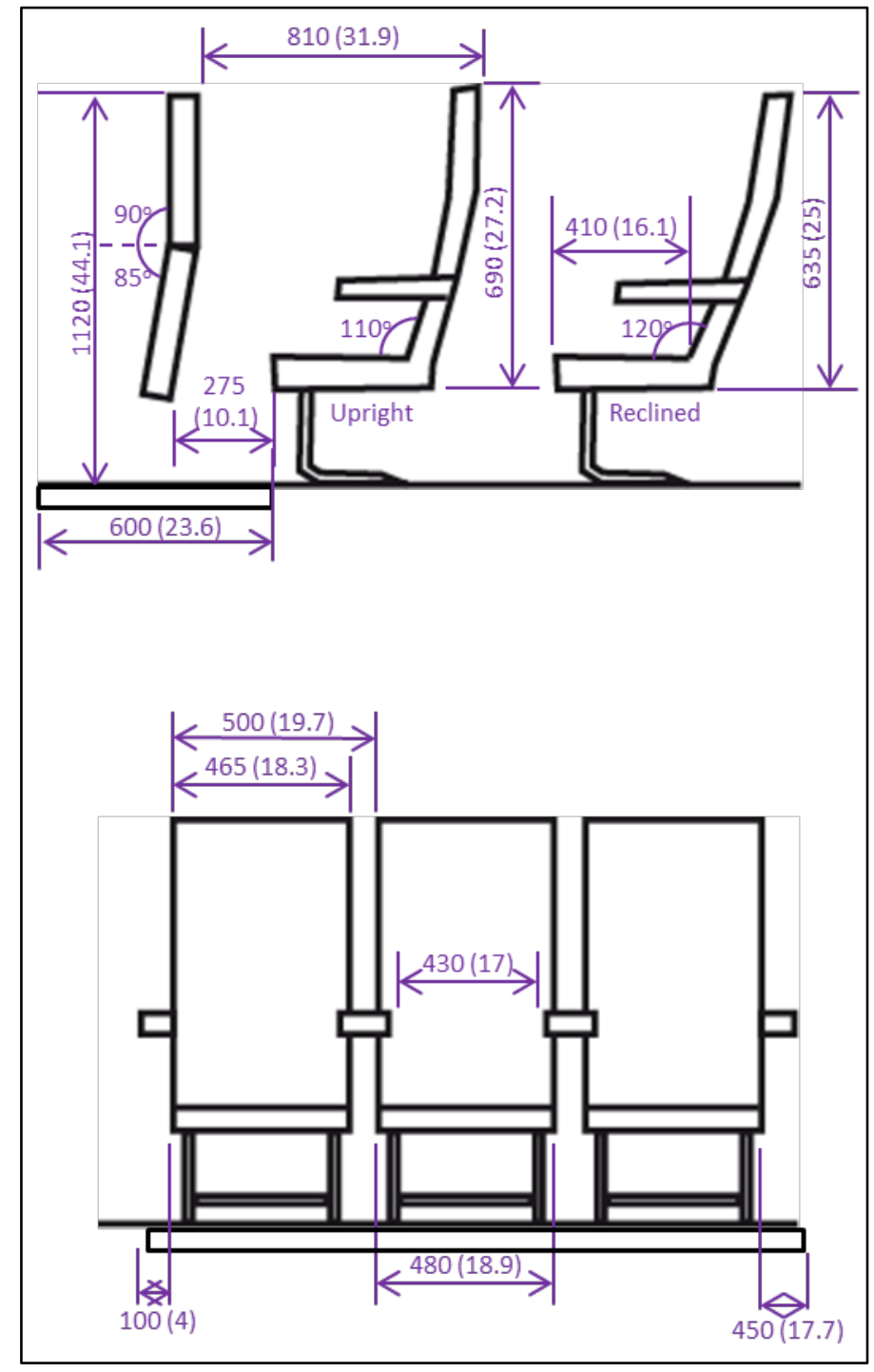

Figure 3 Seat dimensions in $\mathrm{mm}$ (inches). Image not to scale. 


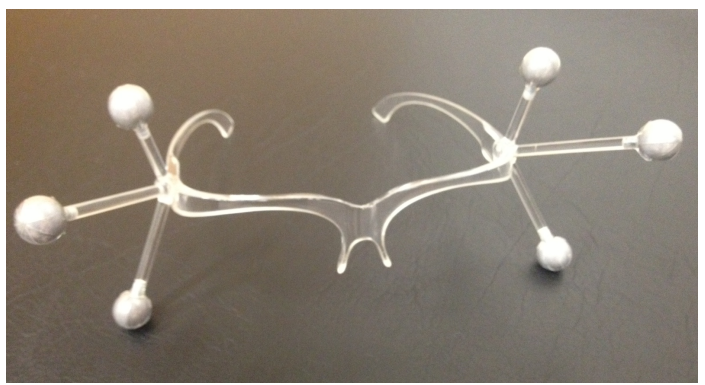

Figure 4 Motion tracking glasses 


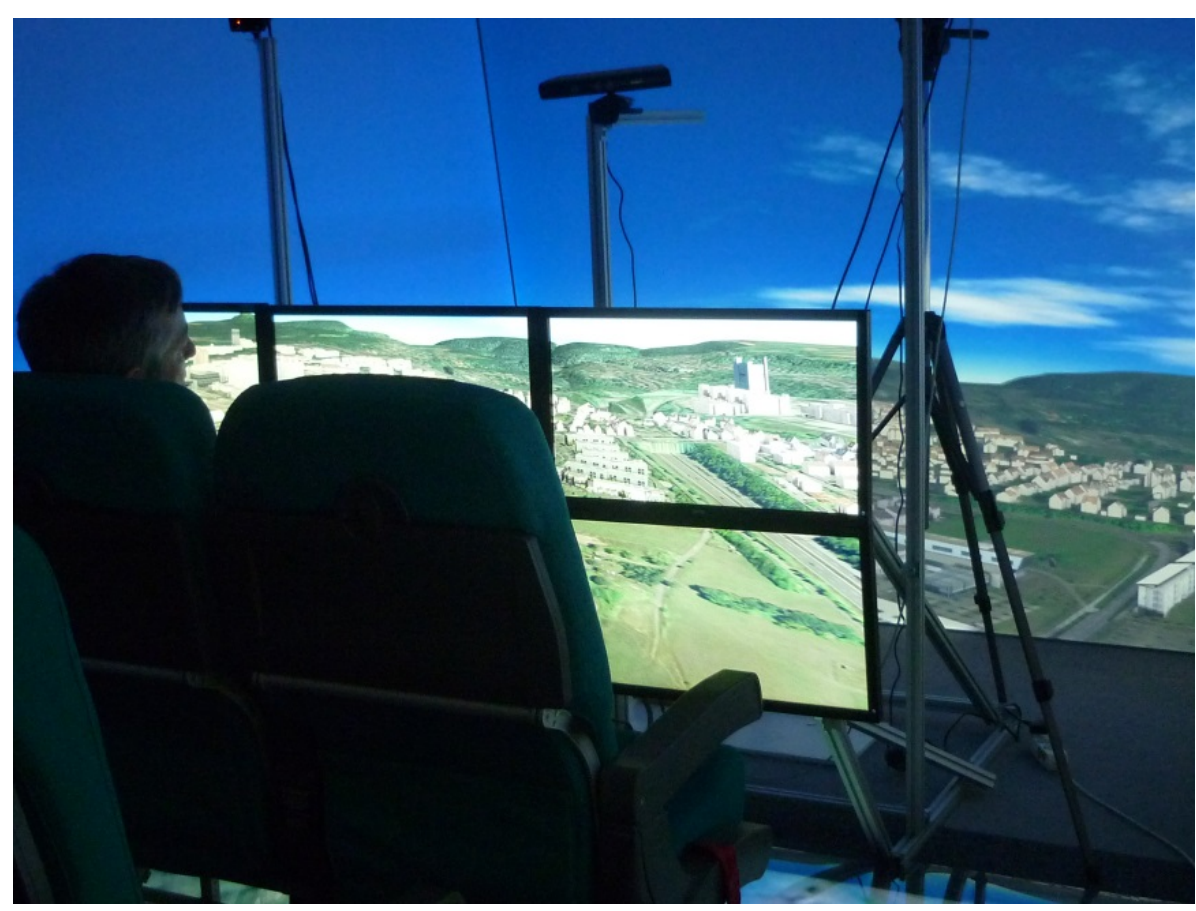

Figure 5 Invisible aircraft (low-level flight) VE 


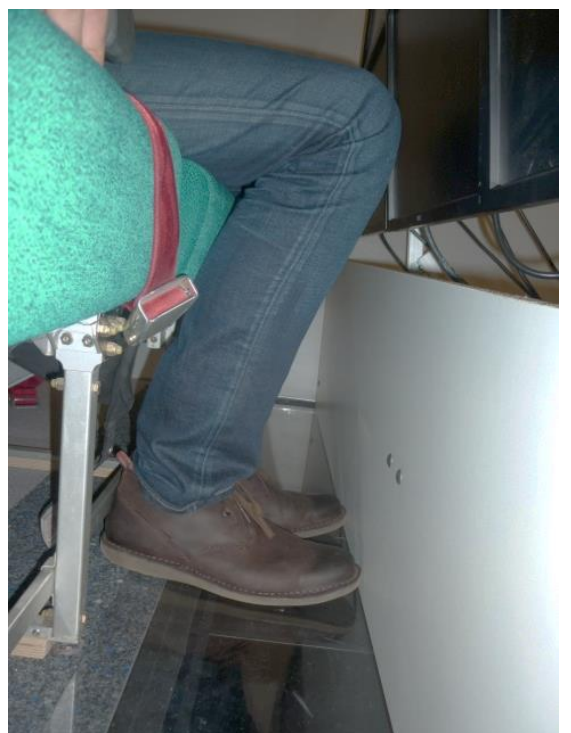

Figure 6 Adjustable board designed to limit the legroom of participants 


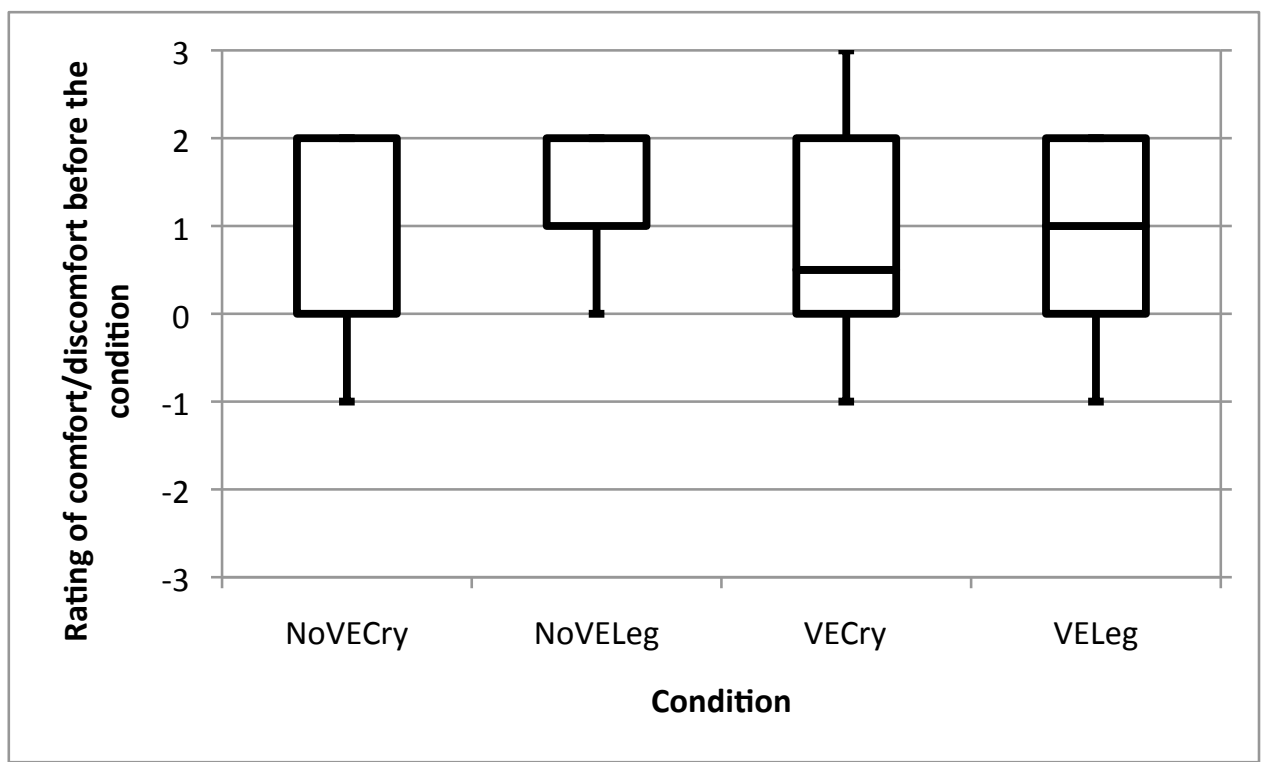

Figure 7 Descriptive statistics for ratings of comfort/discomfort prior to the study 


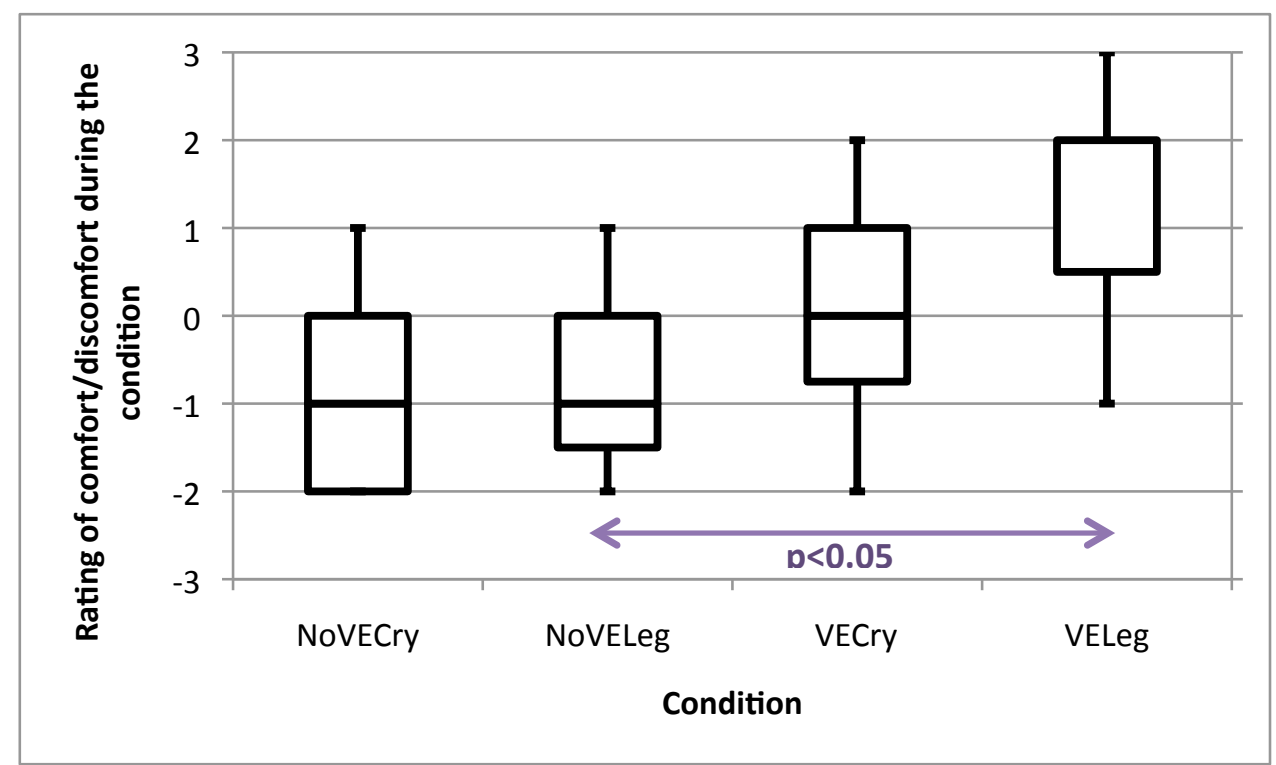

Figure 8 Descriptive statistics for ratings of comfort/discomfort during the study 


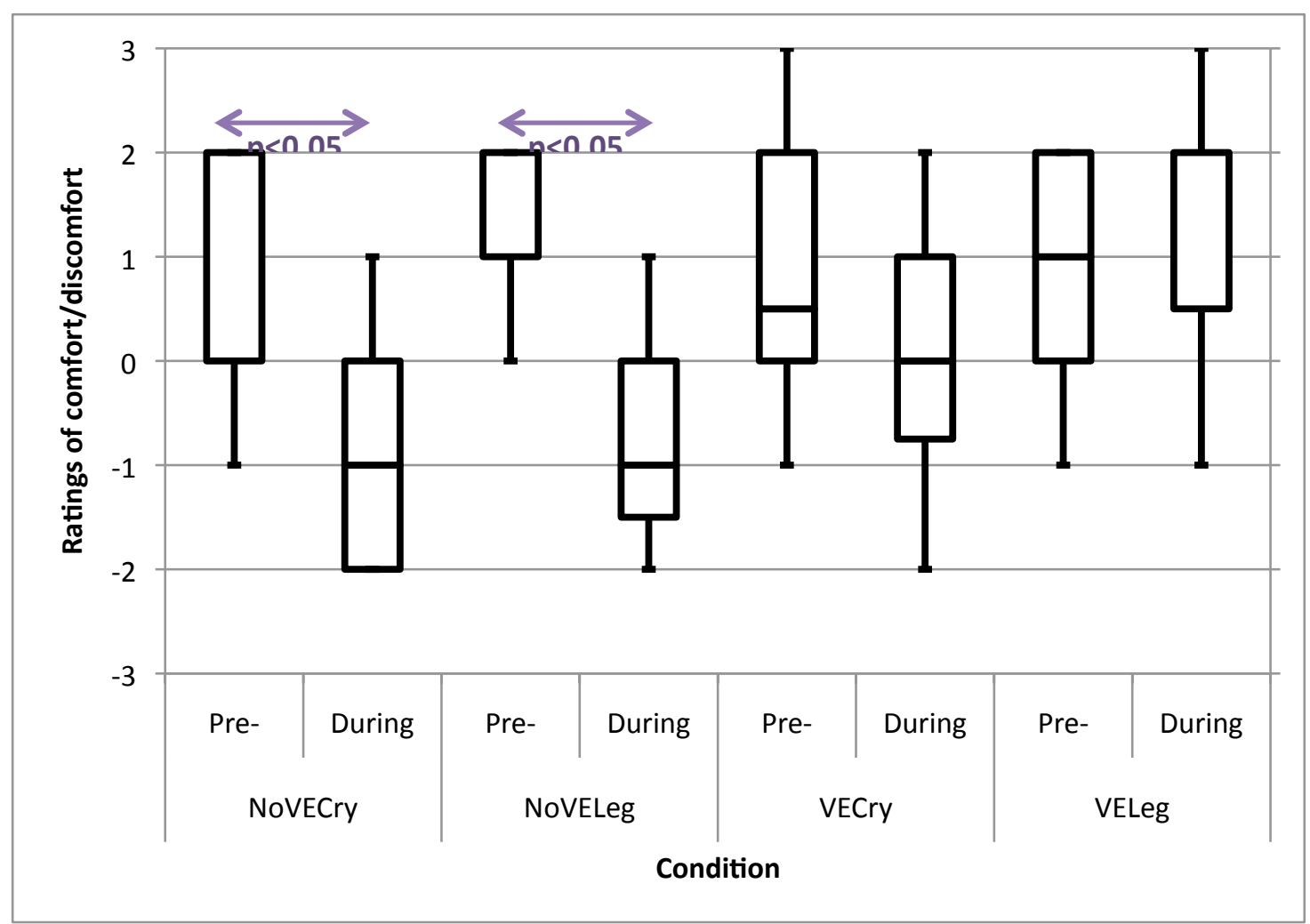

Figure 9 Descriptive statistics for ratings of comfort/discomfort prior to and during the study 